by looking at them, retrieving, or touching them. He responded consistently to his name and to simple words. He identified his own body parts and pictures of Mamma, Sister, and Daddy; and he followed simple commands. His expressive language skills were judged to be at the 12 -month level. He babbled consistently while playing and had expanded his repertoir of sounds to include all vowels and combinations of vowels with some consonants. The babbling still did not have specific communicative purpose. He readily engaged in imitation of consonant-vowel combinations, and occasionally attempted new ones. He communicated primarily through gesture; for example, when he wanted to play ball, he would hand the ball to the person and gesture that it be thrown to him. He spontaneously used the words eye and no and the sound unit ha (hot) for coffee and he imitated simple words.

Because providing a conducive environment for speech and language development had worked so well, such stimulation was continued. When language skills were formally assessed 8 months later, at 2 years, his receptive language ability was at about the 2.5 year level. He used single words and phrases consistently and meaningfully. There was no longer a need for him to rely on gesture to communicate. Qualitative analysis of his expressive language revealed that although his syntactic and grammatic patterns were immature, being characterized by developmental errors, the patterns were not deviant. As might be expected, receptive and expressive vocabulary was limited to objects and activities in his environment. He knew the words cylinder, isolator, sterile, but he did not know horse, ring, bus. He knew few names of animals, furniture, fruits, and vegetables, few adjectives of size and color, and few prepositions. His speech, which was easily understood by all without the aid of contextual cues, was characterized by a few developmental articulation errors. His ability to correct these errors with a minimal amount of stimulation was excellent. Voice quality, rate, resonance, and fluency were appropriate.

It was apparent that $D V$ needed only exposure to an experience and to the verbal symbol which represented it in order to understand and use it meaningfully, and that he, in fact, did not have a problem in retention or generalization. In order to assure further linguistic (specifically, in vocabularly, syntax, and grammar) and conceptual development, continued exposure and expansion of his language and experiential environment would be necessary. Suggestions for carrying out this plan were made to the hospital staff and his family, for he was spending $50 \%$ of the time at his home. For example, the family's dining room table was moved into the room with the isolator so that the patient would get an idea of what it was like to sit at a table and eat a meal. He would also be exposed to the language which takes place in such a situation.

The most recent evaluation was done when $D V$ was 3 years old. He was more attentive and cooperative and it was possible to administer some formal tests. His ability to understand single words; as measured by the Peabody Picture Vocabulary Test (Form B) (16) was at the 2-year, 8-month level. He missed items with which he had little experience, such as baking and cone. On Carrow's Auditory Test for Language Comprehension (10), which assessed understanding of grammatic and syntactic structures, he scored at the 4-year, 8-month level. He understood complex structures but had difficulty with vocabulary such as pianist, farmer, painter and with concepts which were not part of his environment. For example, he indicated that most men are doctors and that when a car breaks down, a doctor will come and fix it. His ability to associate auditory verbal stimuli, as measured by the Auditory Association subtest of the Illinois Test of Psycholinguistic Abilities (28), was at the 3-year, 9-month level. On this test also, unfamiliarity with some of the vocabulary (i.e. bounce, desk, drawer) adversely affected his performance. Auditory perceptual functioning including discrimination (Quiet subtest of the Goldman-Fristoe-Woodcock) (20), sequential memory for digits (Illinois Test of Psycholinguistic Abilities), sentences (Binet) (50), and commands, closure, and blending (Illinois Test of Psycholinguistic Abilities) was judged to be above average: He still had not had a formal hearing test, but his speech and language development and his response to verbal and nonverbal sounds suggested that hearing sensitivity was probably within normal limits. His oral expressive language was excellent in terms of sentence length, syntactic and grammatic structures, vocabulary (when considered in relation to his environment), quality of narration, and motivation to use oral language for communication. His connected speech, which was characterized by a frontal lisp, was intelligible at all times and his voice quality, rate, resonance, and fluency were appropriate. He was beginning to show above average ability to understand graphic symbols, specifically letters and numbers.

Language stimulation will be continued in the nursery school situation, which has been created by the team presently working with him. In this manner, his linguistic and conceptual systems should continue to develop. Progress will be monitored. If necessary, direct work on teaching written language will be introduced at an appropriate time.

Pediat. Res. 11: 85-86 (1977)

\title{
IX. Psychiatric Evaluation
}

\author{
DAVID A. FREEDMAN \\ Department of Psychiatry, Baylor College of Medicine, Houston, Texas, USA
}

From infancy, efforts were made to provide this child with affectionate care and environmental stimulation as much like that of normal children as possible under the circumstances of his limited quarters and the barrier between him and the outside world. For instance, as an infant he could be picked up by means of the isolator gloves, handled, jostled. He has an abundance of play objects, dolls, picture books, coloring books, etc., in the isolator. His isolator has always been placed near a picture window where he can see the flow of traffic. He often recognizes his caretakers as they walk from building to building. As he grew 
older he was provided with a playroom which he could enter by descending several steps. Arrangements were made for the transport of his isolator so that, from the time he was an infant, he has spent about half his time at home with his mother and father caring for him. A window in the vehicle allows him to observe the outside world during transport. When the occasion demands, he is disciplined as are other children. He has been taught to feed himself and has been toilet trained. Several members of the medical staff feel a deep affection for him and one in particular makes a practice of seeing him for a while every night while he is in the hospital.

Nevertheless, because of the plastic barrier between him and his caretakers, he has been deprived of certain experiences which are inevitable in the rearing of ordinary children. Some of these, which have been considered critical for early psychological development (9), include the molding of the infant's body to the mother or caretaker and the mutual ventral to ventral clinging or embracing of another person. In addition, mothering by a relatively constant caretaker has not always been possible since the child spends half of the time in the hospital with a succession of attendants. Other social experiences have necessarily been variable. On the other hand, he has had relative freedom in his limited environment, and has had to rely on himself to get around and explore rather than being picked up and carried. He has never been ill from an infection and has never experienced uncomfortable changes in weather. He has been exposed to an unusual variety of visual and auditory stimulation. The effects of these unusual circumstances of $D V$ 's life on cognitive and affective development to age 3 have been reported elsewhere $(18$, 19). $D V$ 's behavior at 4 years is still consistent with these findings which are summarized below.

There was no evidence of environmental deprivation in the areas of motor development and locomotor activity. In fact, $D V$ showed early indications of precocious development in these areas. At less than 4 months he could squirm to and retrieve objects, sit with slight support, and get up on his hands and knees (6.5-month achievements). At 4 months he coordinated hand and eye (5-month norm). At 6 months he crawled on all fours (10-month norm), recovered objects he dropped, used both hands in coordination, transferred objects from hand to hand, and handled two objects independently (all 8-9-month achievements). At 8 months he sat up alone for long periods (10month norm), stood without support (13-14-month norm), and crawled skillfully (12-15-month norm), could walk alone, and he could also squat or stoop (17-month norm). By 11 months he walked easily and could turn around and sit in a child's chair (18month norm).

Up to 12 months $D V$ manifested a wide range of affective behavior such as pleasure when he was held or tossed about, and anger when he was frustrated. He protested appropriately when he was subjected to the various procedures carried out by the medical team. However, he rarely initiated contact with others by voice or gesture and showed no interest in involving others in his activities. This disregard of his environment, a delay in prelanguage development, and a persisting involvement in rhythmical rocking behavior when he was 8-9 months old led to a reassessment of the quality of the care he was receiving.

A campaign of intensified stimulation, in relation to caretaking activities, social interplay, and language learning, was instituted. A television set was placed near his isolator. A specific caretaking person was assigned to him during his periods of hospitalization. In the hospital and at home he was encouraged to help transfer materials into the isolator and to keep the isolator neat.

Whether because of these efforts or coincidentally, improvements were observed in a few weeks. By the age of 24 months, he was a happy, outgoing, mischievous little boy. Rhythmic selfstimulating behavior was detectable occasionally in the form of muted rocking, but he played actively and displayed a range of affect and capacity for involvement well within the range of normal for 2-year olds. His affective development has continued to progress along lines which would be considered within the normal range for children of his age.

Typical problems for 2-3-year-old children have occasionally emerged. When it was decided that he should be weaned at 26 months, he became irritated at receiving milk from a cup with meals but seemed willing to settle for bottles at nap and bedtime. When he was denied his bottle at nap and bedtime also, his behavior regressed in several ways. Although he had been well on the way to bowel and bladder control, he again became incontinent of feces. He deliberately spilled his milk when it was poured into a cup. Thumbsucking and rocking increased. He would awaken during the night and cry for his nipple and for "Mommy," although up to that time he had never called for his mother. When his bottle was returned to him he was very possessive of it and continued to be irritable, but his normal disposition soon returned. Full continence was established by 33 months, and by 30 months he had given up the bottle at nap and bedtime.

Until his third birthday there was no evidence of genital interest. More recently, however, he has shown some interest in his penis in the form of expressions of pleasure when he handles it -"tickle my tee tee."

Despite the very clear evidence of his intellectual competence, it was not until he was nearly 3 years old that $D V$ showed an interest in leaving the isolator. This is all the more striking because he observed the construction of his playroom, and watched various members of the team entering and leaving it. When he was about 30 months old he did invite a visiting child to open the door and come into the room, but the idea that he might go out did not occur to him until his 35 th month when he expressed the contingency "when I get out of here . . .". Once it occurred to him he used this conditional form repeatedly and in a variety of contexts. Up to the time of this writing, however, he has given no indication of putting the thought into action. His failure to do so is interesting in view of the fact that he is well acquainted with the structure and is physically capable of letting himself out.

When the psychological and intellectual status of this child is compared with those of the fraternal twins reared in isolation in Germany (46) for approximately 2.5 years, interesting facts emerge which may have broad implications for human psychological development. Both sets of observations indicate that isolation under these specific conditions is compatible with average affective development during the first 3 years. The German twins had significant and permanent mental disability which the authors felt may have been due to their extended stay in the isolator. However, the possibility that genetic endowment may affect psychological development in such children cannot be excluded. Other complex factors which could affect development may also be involved. For instance, the twins were not maintained germ free from birth, but were decontaminated and placed in the isolator at the age of 6 weeks. Before that time they were certainly infected. Although no pathogens were isolated, they suffered from jaundice, purulent dermatitis ( $S$. epidermidis isolated), and hemorrhagic diarrhea (49). There can be no absolute certainty that these immune-deficient infants did not already harbor some type of chronic, inapparent infection perhaps similar to the so-called "slow" virus infections (22). There was, however, no diagnostic evidence that this was the case.

The case presented in this report demonstrates that it is possible to rear a child, under these conditions of strict reverse isolation, who can respond with affective, cognitive, and intellectual ability within the normal range of other children up to the age of 4 years. 